\title{
Review on Hydatidosis in Small Ruminant and its Economic and Public Health Significance
}

\author{
Bushura Regassa* \\ University of Gondar, College of Veterinary Medicine and Animal Science, Ethiopia
}

Submission: March 02, 2019; Published: March 29, 2019

*Corresponding author: Bushura Regassa, University of Gondar, College of Veterinary Medicine and Animal Science, Gondar, Ethiopia

\begin{abstract}
Echinococcosis/hydatidosis is a zoonotic parasitic disease caused by the dog tapeworm Echinococcus and its larval stage, the hydatid cyst. It is characterized by the formation of variably sized cysts in the visceral organs of the intermediate hosts and adult tapeworm in the intestine of dogs. The disease is chronic and affects all kinds of food animals, including herbivorous and omnivorous mammals. The distribution of $\mathrm{E}$. granulosus is higher in developing countries, especially in rural communities where there is close contact between the dog, the definitive host, and various domestic animals, which may act as intermediate hosts. Echinococcosis is associated with severe morbidity and disability and is one of the world's most geographically widespread zoonotic diseases. Hydatid disease results in loss of millions of money in terms of public health each year and lowered productivity of infected animals. The objective of this seminar paper is to review the epidemiology, pathogenesis, diagnosis, control and prevention of hydatidosis and its public health and economic impact. The life cycle is complex, involving two hosts and a free-living egg stage. The dynamics of the transmission of the parasite are determined by the interaction of factors associated with these two hosts and with the external environment. The effect of the hydatid cyst on the intermediate host depends on the size and location of the cyst. In the intermediate host, diagnosing hydatidosis is possible through scanning, radiology, serology and postmortem examination. Unfortunately, surgery is the treatment of choice at present, but several of the benzimidazole compounds have been shown to have efficacy against the hydatid cyst in the intermediate host. Therefore, Echinococcosis can be controlled through dosing dogs, inspecting meat and educating the public on the risk to humans and on avoiding feeding offal to dogs, as well as introducing legislation.
\end{abstract}

Keywords: Definitive host; Echinococcus granulosus; Hydatidosis; Intermediate host; Zoonosis

Abbreviations: CDC: Centre of Disease Control; CE: Cystic Echinococcosis; DNA: Deoxyribonucleic Acid; ELISA: Enzyme Linked Immuno Sorbent Assay; ETB: Ethiopian Birr; OIE: Office International des Epizootics; PCR: Polymerase Chain Reaction; US: United State; WHO: World Health Organization

\section{Introduction}

Echinococcosis is a zoonotic parasitic tapeworm infection caused by the larval stage of several species belonging to the genus Echinococcus, the dog tapeworm [1]. Domestic animals such as camels, cattle, goats, and sheep which live in close contact with dogs are implicated as one of the important contributors of zoonotic diseases to humans [2]. It is characterized by the formation of variably sized cysts in the visceral organs of the intermediate hosts and adult tapeworm in the intestine of dogs [3]. The disease is chronic and affects all kinds of food animals, including herbivorous and omnivorous mammals. Humans can accidentally become hosts by ingesting the eggs of Echinococcus granulosus. In humans, the cysts develop in the liver and lung but other organs and tissues may also become affected [4]. The public health importance of echinococcosis includes cost of hospitalization, medical and surgical fees, losses of income and productivity due to temporal incapacity to work,

social consequences, due to disability and mortality [5]. Cystic echinococcosis or hydatidosis is a neglected cyclozoonotic disease affecting humans and their livestock, thereby causing significant socioeconomic and public health impacts, mostly in developing countries [6].

The disease continues to occur in many countries especially in the developing world, where they mostly affect the poorest segment of the human population. It represents a significant global human disease burden in poor pastoral communities. Echinococcosis is associated with severe morbidity and disability and is one of the world's most geographically widespread zoonotic diseases [7]. The disease has a worldwide distribution and its prevalence varies among regions due to climate difference and agro ecology, level of education, and development condition [8]. The distribution of E. granulosus is higher in developing countries, especially in rural communities 
where there is close contact between the dog, the definitive host, and various domestic animals, which may act as intermediate hosts [3]. Currently, ten (G1-G10) and lion strain (E. felids) genetically, biologically and morphologically distinct strains of $\mathrm{E}$. granulosus have been identified from different parts of the world [9]. The different strains of the parasite were reported to have different epidemiological and socio-economical significances, and geographical ranges [3]. Among the ten different strains of E. granulosus so far characterized, seven of them (G1, G2, G3, G5, G6, G7, and G9) were reported to have public health importance. In Africa, six strains of E. granulosus, the common sheep strain (G1), Tasmanian sheep strain (G2), horse strain (G4), cattle strain (G5), camel strain (G6), and lion strains (E. felids) were reported. From these, four of them (G1, G2, G5 and G6) were reported to infect humans in different parts of the world [10].

Hydatid disease not only results in loss of millions of money in terms of public health each year, but also it worsens the protein deficiency for human consumption in terms of condemned organs, and lowered productivity of infected animals [11]. Globally, cystic echinococcosis was estimated to cause human and livestock associated annual economic losses of at least US $\$ 193,529,740$ and US $\$ 141,605,195$, respectively [12]. The disease incurs economic losses in meat sector, effective control and prevention measures should be introduced to minimize the risk of public health hazard and curb the incurred economic losses. The current first drug of choice is praziquantel, which is recommended for goats and sheep. The drug is highly effective against immature and mature intestinal stages, but the drug is not ovicidal [13]. Effective control of hydatid disease is based on presentation by breaking the cycle between definitive and intermediate hosts. This has been demonstrated in a number of well documented control campaigns concerned with Echinococcus granulosus maintained in domestic life cycle patterns [14]. The key to success is health educations that elicit community participation [15]. Therefore, the objectives of this seminar paper are to overview the public health importance and economic impact of cystic echinococcosis in small ruminants.

\section{Etiological Agents and Morphology}

At present, four species of the genus Echinococcus are recognized and regarded as taxonomically valid: E. granulosus (cystic hydatidosis), E. multilocularis (multivesicular hydatidosis), E. vogeli (polycystic hydatidosis) and E. oligarthrus [4]. These four species are morphologically distinct in both the adult and the larval stages. In addition, several different strains of E. granulosus and E. multilocularis are recognized [16]. Adult Echinococcus is a very short tapeworm only rarely more than mm long and usually has no more than six segments. Like all tapeworms, Echinococcus has no gut and all metabolic interchange takes place across the syncytial outer covering tegument. Interiorly, the adult Echinococcus possesses an attachment organ, the scolex, which has four muscular suckers and two rows of hooks, only large and one small, on the rostellum [17]. The body or strobila is segment- ed and consists of a number reproductive unit (proglottids), which may vary in number from two, to six. The adult worm is hermaphrodite with reproductive ducts opening at a common, lateral, genital pore, the position of which may vary depending on species and strain. There is a prominent cirrus sac, which may be horizontal or titled anteriorly and the vitellarium is globular. The uterus dilates after fertilization, eventually occupying most of the terminal segment when the eggs are fully developed [18].

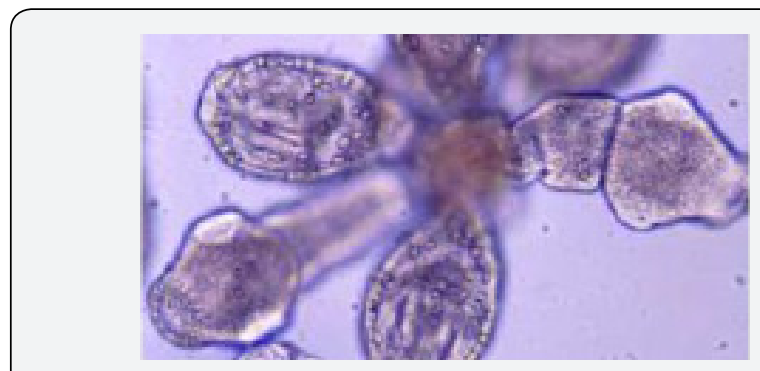

Figure 1: Protoscolices from hydatid broad capsule [37].

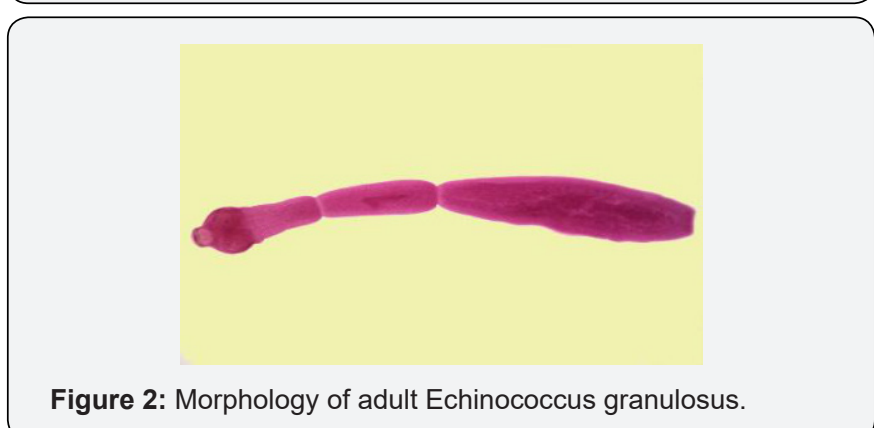

The eggs are ovoid (30 $3 \mathrm{~m}-40 \mu \mathrm{m}$ diameter), consisting of a hexacanth embryo (oncosphere $=$ first larval stage) surrounded by several envelopes, the most noticeable one being the highly resistant keratinized embryophore, which gives the egg a dark striated appearance. The eggs of Echinococcus are morphologically indistinguishable to those of other tapeworms of the genus Taenia [18]. The metacestode (=second larval stage) basically consists of a bladder with an outer acellular laminated layer and an inner nucleated germinal layer, which may give rise by asexual budding to brood capsules. Protoscoleces arise from the inner wall of the brood capsules. The structure and development of the metacestode differs between the four species of Echinococcus [18].

Sheep are typically infected with multiple polymorphic E. granulosus cyst mainly localized in the liver and lung but, the spleen, heart, kidney, omentum, and other organs can also be affected. Similarly, in goats, even though the liver and the lung are the main predilection sites, hydatid cysts have also been recorded in the spleen, heart, brain, and marrow cavity of bone occasionally [19]. Hydatid cysts grow slowly and usually take several years to develop to a size, where they may cause disease and symptom in animals. Fertile cyst may occur within about 6 months in mice, 10-12 month in pig, but about 2-4 years in sheep [17]. 


\section{Life cycle of Echinococcus granulosus}

Echinococcus spp. requires two mammalian hosts for completion of its life cycle. Gravid proglottids or free eggs are passed along with the feces of the definitive host, a carnivore. The adult tapeworm is found in parts of small intestine of the definitive host, from where segments containing eggs are passed with the feaces. When the eggs are ingested by intermediate hosts like cattle, sheep, goats, pigs, and camel in which the metacestode develops, the onchospheres penetrates the wall of the small intestine. A hormonal secretion from the onchospheres aids the penetration in to the intestine. Upon gaining access to a venue, the onchospheres is passively transported to the liver, where some are retained, others reach the lungs, and a few may be transported further to the kidney, spleen, muscles, brain, and other visceral organs. Once the onchospheres has reached its final location, it develops into the metacestode stage (hydatid cyst). The hydatid cyst develops slowly over several months, forming an outer laminated membrane called the germinal layer. From the germinal membrane brood capsules develop, each containing one or several invaginatinated head (protoscolises) that can develop into the adult tapeworm upon ingestion by the definitive host [15]. The life cycle is completed when a dog ingests hydatid cysts containing protoscolices. Following ingestion, protoscolices evaginate, penetrate deeply between the villi in to the crypts of Lieber Kuhn, and develop to maturity in about 47 days [4].

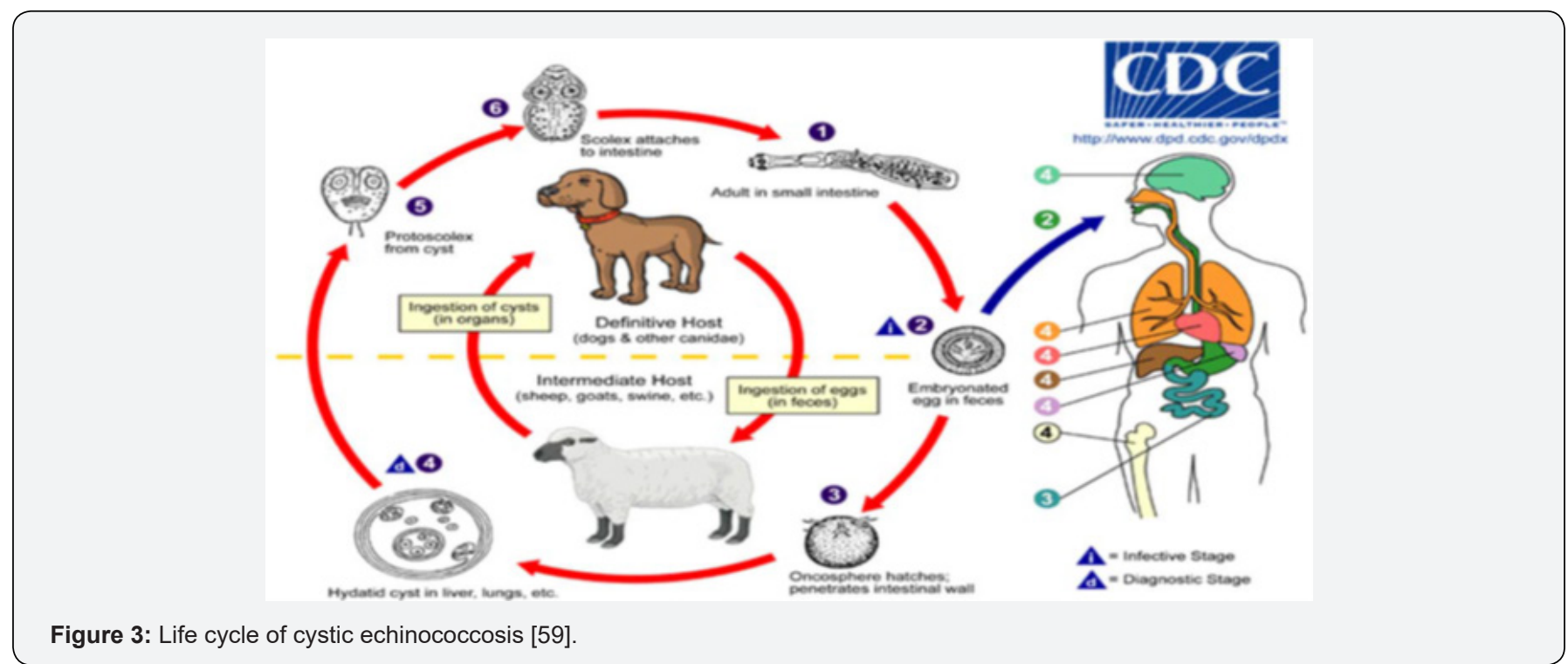

Epidemiology: Hydatidosis due to E. granulosus commonly prevalent in sheep-raising areas of the Mediterranean, Australia, New Zealand, South Africa, South America and the Middle East including Saudi Arabia [20]. In Africa, the disease is reported more commonly in cattle raised in a free range associated intimately with dogs [21].

Mode of transmission to intermediate hosts: The eggs enter into the intermediate hosts by the ingestion of contaminated grass, water, vegetables, and others. It has been shown that flies and possibly other insects contaminated during feeding may mechanically transport the eggs over considerable distance. The definitive hosts are infected by the ingestion of offal's contaminated by fertile and viable hydatid cysts [22].

In developing countries, due to lack of effective meat inspection, and also a backyard slaughter practices, the hydatid cyst infected visceras are deliberately left for home and stray dog's consumption. This type of unhygienic practice plays a major role in the maintenance and transmission of the disease in domestic ruminants and humans. This is particularly true in sub-Saharan Africa countries including Ethiopia [23].
Host range: It is likely that Echinococcus granulosus originally completed its life cycle among wild animals in a sylvatic cycle that involved, for example, wolves and cervids or lions and warthogs. It has now adapted into a domestic cycle, however, commonly involving dogs and sheep [4]. As Echinococcus granulosus has little host specificity with regard to intermediate hosts, hydatid cysts have been seen in a wide range of mammals, including domestic ruminants, camels, giraffe's pigs, equines, elephants, hippopotamuses, marsupials and different types of deer, as well as humans [24].

Risk factor: Certain deep-rooted traditional activities have been described as a factor associated with the spread and high prevalence of the disease in some areas of the country. These can include the wide spread backyard slouther of animals, the corresponding absence of rigorous meat inspection procedures, the long-standing habit of feeding domesticated dogs with condemned offal and the subsequent contaminance of the life cycle of E. granulosus which is the causative of cystic hydatidosis and consequently the high rate of infection of susceptible hosts [25]. 
Three kinds of epidemiological cycles are known: rural type, sylvatic type and urban type. Rural type: this is the most frequent and is concerned with domestic dogs and cats and intermediate hosts which are usually domestic animals. Man is infected, directly or indirectly from dogs and cats in villages or on farms. Sylvatic type: This cycle is completed through wild canidae and felidae and their wild prey (Wild rodents). This is the most frequent type for Echinococcus multi locularis and man is indirectly infected by the alveolar form of this disease, from wild canidea and felidae. Urban type: this cycle is completed through the domestic cat and mice; it has been recognized for some time for alveolar echinococcosis [4].

\section{Pathogenesis}

Hydatid cyst is typed according to their stage of development, namely primary and secondary cystic echinococcosis. The first occurs after the ingestion of eggs of E. granulosus and gives rise to the formation of hydatid cysts in different organs of the body, while the second occurs by the rupture of the primary CE due to trauma. In this condition, the protoscolices are carried out by the blood to different organs and develops to secondary hydatid cyst [26]. Calcification can occur in pericyst, mother cyst, and daughter cyst. The endocysts calcification indicates the cyst is none viable. The calcification of the pericyst can occur in half of the cyst at all stage of development [27].

The cyst of E. granulosus vary greatly in size and shape (typically unilocular, but sometimes multilobed or multilocularis), and may be present in large numbers in one or several organs. The location of cysts and cyst morphology is controlled not only by the host factors, but also by parasite factors such as the strain of E. granulosus involved. Usually the host and the metacestode of Echinococcus coexist well. Initially, following infection, there is a cellular response from the host). This resolve and causes to develop a fibrous capsule (adventitial layer) around the parasite, which enlarges to accommodate the cyst as it grows. Under certain circumstances, the cellular response from intermediate host is protracted resulting in the death of the parasite [28]. Displacement of the lung or liver tissue and fibrous of the area surrounding the cyst, as well as pressure placed on the organs as a result of the hydatid cyst increasing in size during the life of intermediate host, results in pathological tissue changes. Occasionally, larvae localize in the kidney, spleen or brain tissue where their effect are more severe and often fatal [29].

\section{Clinical signs}

Infection with Echinococcus granulosus cyst in the intermediate hosts are typically asymptomatic, except for a small number of cases with chronic and heavy infection. The effect of hydatid cyst on the intermediate host depends on the size and location of the cyst. If large cyst is located in an area of the body, with rigid bounders, such as the brain or lungs, the consequences can be very serious [30]. Since the cyst is slow in growing and animals are often slithered before it manages to create sufficient pressure on the tissue or organs. Fever and generalized pruritis are systemic symptoms often associated with hydatid disease. Rupture of cysts, particularly into serosal cavities, may cause acute and sometimes fatal anaphylactic reaction [31]. The adult Echinococcus is considered to be rather harmless to the definitive host, except when it occurs in large numbers, which may cause severe enteritis. The effect of hydrated cyst on the intermediate host depends on the size and location and location of the cyst. There are few available data on the clinical effects of the cystic hydatid disease in animals since the cyst is slow in growing and animals are often slithered before it manages to create sufficient pressure on the organs [32].

\section{Diagnosis and Treatment}

In the definitive host, a post-mortem examination is the most reliable method of diagnosis. There is usually no early parasitological evidence for the presence of cysts in organs or tissues and in most cases the early stage of infections are asymptomatic. Over the last decade diagnosis of hydatid disease was improved due to the use of imaging techniques including ultrasonography, computed tomography (CT scanning) and magnetic resonance imaging (MRI) supported by immunological assays for confirmation of clinical diagnosis [33]. Recently, a PCR for specific detection of DNA from E. granulosus egg has been developed [34]. Immuno diagnosis involves the detection of parasite antigens in feces (coproantigens) and serum antibody detection. ELISA has been described for several groups for the detection of coproantigens released by cestodes, including Taenia species of dogs, and humans [23]. Treatment comprises mainly surgical intervention or percutaneous treatment and/ or high dose, long-term therapy with albendazole alone or in combination with praziquantel [35].

\section{Control and Prevention}

Echinococcosis can be controlled through preventive measures that break the life cycle of between the definitive and intermediate hosts. These measures include a complete deprivation of dogs from the access of infected raw offal's by proper disposal of hydatid cysts possessing condemned offal's at abattoirs, local slaughterhouses, back yards and on farms. Further control methods include introduction of appropriate meat inspection, establishment of local slaughterhouses, education of the people, effective implementation of legislative measures, burning or burial of condemned offal's and sterilization of offal's, if it is going to be used as dog food [36]. Specific control measures including stray dogs' control, registration of all owned dogs, spaying of bitches and treatment of all (or most) dogs with praziquantel at predetermined intervals for example every 6-8 weeks [37]. Prevention can be achieved by strict hygiene measures like hand washing after animals handling, in particular dogs [26]. Control of movements of food animals and dogs from the infected areas to the "clean" ones; marking and control of movements of animals from infected flocks or herds [38].

Application of an effective vaccine to reduce hydatid infection in livestock would be likely to have a substantial impact on the 
rate of transmission of the disease to humans [39]. Echinococcus vaccines would ideally prevent oncosphere development to hydatid cysts in sheep, and thus stop the development of adult gravid tapeworms in dogs [40]. Large controlled studies with sheep have shown that vaccination with a recombinant oncospheral EG95 induces high degree of protection, reducing the cyst numbers in vaccinated animals by approximately 90 to $100 \%$. A high degree of immunity (about $80 \%$ ) persists for 6 months (in the absence of reinfection), and pregnant ewes vaccinated before lambing transfer high levels of. There is no vaccine for dogs, although research is under way [41]. An effective vaccine for ovine echinococcosis has been developed [39] and may become available soon. Community ultrasound surveys have been used to raise awareness in communities considered to be at risk [42]. Currently there are no human vaccines against any form of Echinococcosis. However, there are studies being conducted that are looking at possible vaccine candidates for an effective human vaccine against Echinococcosis [43].

\section{Public Health Significance}

Cystic echinococcosis (CE) caused by larval stages of Echinococcus granulosus is one of the most common zoonotic diseases associated with severe economic losses and great public health significance worldwide [44]. Echinococcus infections are estimated to affect approximately two to three million people worldwide, with Africa amongst the primarily endemic regions [45]. Humans are infected by ingesting eggs of E. granulosus through contaminated food, water and soil, or through direct contact with dogs [46]. The role of dogs in the spread of the disease has also been reported by other researchers in Ethiopia [47]. CE in humans has frequently been reported from different regions of the country [48]. The disease is more common in rural areas, where dogs and domestic animals live in very close association [49]. Most CE cases in humans are caused by the sheep strain (GI) and camel strain (G6) of E. granulosus [50]. In humans the cyst may reside and grow in liver, lung and other visceral organs. Occasional rupture of the cysts often leads to sudden death because of anaphylaxis, hemorrhage and metastasis [51].

Infections in humans occur by ingesting eggs through hand to mouth transfer of eggs after contact with the faces or contaminated fur of infected dogs [46]. The disease also has a wider public health importance. Humans are accidental intermediate hosts [52]. The highest burden of human CE occurs over a large more or less contiguous transmission Zone from North Africa, Near East, Middle East, Central Asia, eastern Russia and western China [36].

\section{Economic Significance}

Cystic echinococcosis in livestock causes considerable economic losses due to condemnation of affected animal organs at the slaughterhouse, production losses (reduction in live weight gain, yield of milk, fertility rates, value of hide and skin) and losses related to treatment of animals and humans [53]. The economic burden of $\mathrm{CE}$ on the global livestock industry alone has been estimated to be over $\$ 2$ billion per annum, such losses are of particular importance in Ethiopia, which has low economic output with a per capita income of less than one US dollar per day [54-60]. The difference in economic losses agreed with the variation in the prevalence of the disease, mean annual slaughter rate in different abattoirs and variation in retail, market price of organs. The economic loss due to cystic echinococcosis varies according to several works conducted so far in different parts of the country. Recent study recorded a loss of 287,179.99 ETB from organ condemnation and carcass weight loss in sheep and goats in Hashim Nur's export Abattoir in Debrezeit.

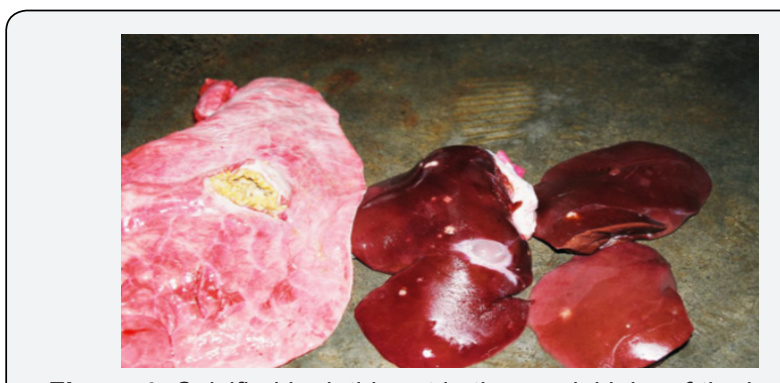

Figure 4: Calcified hydatid cyst in the caudal lobe of the lung of male sheep (right) and Small to medium size hydatid cysts in the livers of sheep (left) [64].

\section{Conclusion and Recommendations}

Hydatidosis is an important zoonosis and is a serious public health and economic problem throughout the world. In domestic ruminants it inflicts enormous economic damage due to the condemnation of affected organs and lowering of meat, milk and wool production. The disease is chronic and affects all kinds of food animals, including herbivorous and omnivorous mammals. The public health importance of echinococcosis includes cost of hospitalization, medical and surgical fees, losses of income and productivity due to temporal incapacity to work, social consequences, due to disability and mortality. The distribution of E. granulosus is higher in developing countries, especially in rural communities where there is close contact between the dog, the definitive host, and various domestic animals, which may act as intermediate hosts.

Based on the above conclusion the following recommendations are forwarded:

a. In endemic areas of hydatidosis, the subspecies and strain identification of E. granulosus, followed by immunological study of infected animals should be carried out to promote the production of vaccines against the adult parasite in the dogs.

b. The government should Initiate and involve pertinent agencies such as public health and other related agencies.

c. The Ministry of Public Health has to increase the awareness of public regarding risk factors for transmission of the parasite.

\section{Acknowledgement}

First and for most my special thanks goes to the Almighty God, who are the corner stone and the pillar in sustaining my life. 
Secondly my great thanks go to my lovely family, who supports me in many ways until now, and thirdly my thanks goes to my adviser Dr. basaznew bogale, for his continuous encouragement, valuable suggestion, guidance and critical review of the paper. My sincerely gratitude is also extends to my special friends who helped me by suggestion and logistic support specially Meksud Mohammed, Feyera Hora and Numan Jemal.

\section{References}

1. Surhio AS, Bhutto B, Gadahi JA, Akhter N, Arijo A (2011) Research opinions in animal and veterinary sciences. Study on the prevalence of caprine and ovine hydatidosis at slaughter houses of Larkana, Pakistan. Roavs 1: 40-43.

2. Abdel-Rahman N, Daragmeh N, Adwan M, Al-Qaoud D, Abdel Hafez SK (2001) Human Cystic Echinococcosis in the west bank of Palestine: Surgical incidence and Sero- epidemiological study. p. 19.

3. Eckert J, Deplazes P (2004) Biological, epidemiological and clinical aspects of Echinococcus, a zoonosis of increasing concern. Clinical. Microbiology Review 17: 107-135.

4. Soulsby EJ (1986) Helminth, Arthropods and Protozoa of Domesticated Animals ( $7^{\text {th }}$ edn), Baillere Tindal London, UK, pp. 119-124.

5. Azlaf R, Dakkak A (2006) Epidemiological study of the cystic echinococcosis in Morocco. Veterinary Parasitology 137: 83-93.

6. Zhang W, Wen H, Li J, Lin R, McManus DP (2012) Immunology and immunodiagnostic of Cystic echinococcosis. p. 10.

7. Cringoil G, Rinaldi L, Musella V, Veneziano V, Maurelli MP, et al. (2007) Geo-referencing livestock farm as tool for studding cystic echinococcosis epidemiology in cattle and water buffaloes from south Italy. Geospatial 2: 105-111.

8. Jenkins D, Lallen J, Goullet M (2008) An encroachment of Echinococcus granulosus into urban areas in eastern Queensland, Australia. and Australian Veterinary Journal 86: 294-300.

9. Grosso G, Gruttadauria S, Biondi A, Marventano S, Mistretta A (2012) Worldwide epidemiology of liver hydatidosis including the Mediterranean area. World Journal Gastroenterology 18: 1425-1437.

10. McManus DP (2006) Molecular discrimination of taeniid cestodes. Parasitology. Internal 55: 31-37.

11. Rokni MB (2009) Hydatidosis in Iran. Iran Journal of Parasitology 4: 1-16.

12. Budke CM, Deplazes P, Torgerso, PR (2006) Global socioeconomic impact of cystic echinococcosis. Emer. Infectious. Disease 12: 296-303.

13. OIE (2001) (Office International Des Epizootics) WHO/OIE Manual on Echinococcosis in Humans and Animals in a public health problem of global concern, France, p. 53-64.

14. Gemmell MA, Lawson JR (1986) Epidemiology and control of hydatid disease. The biology of Echinococcus and hydatid disease (R. C. A. Thompson, Ed.). Allen and Unwin, London. Pp. 189-216.

15. Schantz PM (2005) Progress in Diagnosis, Treatment and Elimination of Echinococcosis and Cysticercosis. Parasitology. Internal 20: 30-37.

16. FAO (1982) Echinococcosis/Hydatidosis. Surveillance, Prevention and control. FAO/WHO, guide lines. FAO Animal production and Health, Paper no.29 Rome, Italy, p. 1-50.

17. Thompson RCA (1986) Biology and systematics of Echinococcus granulosus. In: The biology of Echinococcus and hydatid disease. Thompson (Eds.), London, UK, George Allen and Unwin. p. 5-6.

18. Urquhart GM, Armour J, Duncan JL, Dunn AM, Jennings FW (1996) Veterinary Parasitology ( $\left.2^{\text {nd }} e d n\right)$, Blackwell Science Ltd, UK, 122: 128129.
19. Thompson RCA, Eckert J (1983) Observations on Echinococcus multilocularis in the definitive host. Z. Parasitenkd, 69: 335-345.

20. Toulah FH, El-Shafaeis AA, Alsolami MN (2012) Prevalence of Hydatidosis among slaughtered animals in Jeddah, Kingdom of Saudi Arabia. J Egypt Soc Parasitology 42(3): 563-572.

21. Abebe F, Yilma J (2013) Estimated annual economic loss from organs condemnation, decreased carcass weight and milk yield due to bovine hydatidosis. Ethiopian Veterinary Journal 16(2): 1-14.

22. Schantz PM (1990) Parasite zoonosis in perspective. International Journal of Parasitology 21: 165-166.

23. WHO/OIE (2002) by Eckert J, Gemmell MA, Meslin FX, Pawlowski (Eds.), Manual on echinococcosis in humans and animals, a Public Health Problem of Global Concern p. 77-78.

24. Rausch RL (1995) Life cycle patterns and geographical distribution of Echinococcus species. In Echinococcus and hydatid disease. In: Thompson RCA, Lymbery AL (Eds.), CAB International, Wallingford, Oxon, UK, pp. 88-134.

25. Jobre Y, Lobago F, Tiruneh R, Abebe G, Dorchies P (1996) Hydatidosis in three selected regions in Ethiopia: An assessment trial on its prevalence, economic and public health importance. Review Medicine Veterinary 147: 797-804.

26. Parija SC (2004) Text book of Medicine and Parasitology, Protozoology and Helminthology. $\left(2^{\text {nd }} \mathrm{edn}\right)$, India publishers and Distributors, India, New Delhi, India, p. 5-39.

27. Khuroo MS (2002) Hydatid disease, current status and recent advances. Ann Saudi Medicine 122: 56-64.

28. Thompson RCA, Allsopp CE (1988) Hydatidosis Veterinary perspectives and annotated bibliography. C.A.B. International, Wallingford, Oxon, UK, pp. 246.

29. DNR (Department of National Resource) (2009) Echinococcosis (Cystic hydatidosis) p. 2-4.

30. Daryani A, Alaei Arab R, Sharif M, Dehghan MH, Ziaei H (2007) The prevalence intensity and viability of hydatid cyst in slouthered animals in the Arab provinces of North West Iran. Journal of helminthology 18: 13-17.

31. Parry E, Godfrey DM, Gill (2004) Principles of Medicine in Africa. ( $3^{\text {rd }}$ edn), Cambridge, USA, pp. 406-408.

32. Dunn A (1987) Veterinary Medicine, Addis Ababa University, Ethiopia. Handbook for Ethiopia. p. 2.

33. Zhang W, Li J, Mc Manus DP (2003) Concepts in immunology and diagnosis of hydatid disease. Clinical. Microbiology. Review. p. 18-36.

34. Abbasi I, Branzburg A, Campos PM, Abdel Hafez SK, Roul F, et al. (2003) Copro-diagnosisis of Echinococcus granulosus infection in dogs by amplification of newly identified repeated DNA sequence. American Journal of Tropical Medical. Hygiene 69: 3254-3360.

35. Brunetti E (2010) Expert consensus for the diagnosis and treatment of cystic and alveolar echinococcosis in humans. Acta Tropica 114(1): 1-16.

36. Craig PS, Mc Manus DP, Lightowlers MW, Chabalgoity JA, Garcia HH, et al. (2007) Prevention and control of Cystic echinococcosis. Lancet Infectious Disease 7: 385-394.

37. Pedro M, Peter MS (2009) Division of Parasitic Diseases, Coordinating Center for Infectious Diseases, Atlanta, Georgia, and USA. Center of Disease Control and Prevention 13: 125-133.

38. Vuitton DA, Economides P, WHO-IWGE EurEchinoReg Network (2011) Echinococcosis in Europe Web site, Echinococcosis in Western Europe, a risk assessment/riskmanagement approach.

39. Lightowlers MW (2006) Cestode vaccines: origins, current status and future prospects. Parasitology 133: 27-42. 
40. Philip S, Craig PS, McManus DP, Marshall W, Lightowlers MW, et al. (2007) Review on prevention and control of cystic echinococcosis. Lancet Infectious Disease 7: 385-394.

41. Petavy A (2008) An oral recombinant vaccine in dog against Echinococcus granulosus, the causative agent of human hydatid disease: a pilot study. PLoS Neglected Tropical Diseases 2(1): e125.

42. Kachani M (2003) Public health education: importance and experience from the field. Educational impact of ultrasound screening surveys. Acta Tropica 85: 263-269.

43. Daryani A, Sharif M, Amouei A, Nasrolahei M (2009) Fertility and viability rates of hydatid Disease in Wales. Br Medical Journal 312 : 674-675.

44. Romig T, Omer RA, Zeyhle E, Hüttner M, Dinkel A, et al. (2011) Echinococcosis in sub-Saharan Africa: Emerging complexity. Veterinary Parasitology 181: 43-47.

45. Cummings H, Rodriguez-Sosa M, Sat Oskar AR (2009) Hydatid disease. In Sat Oskar AR, Simon GL, Hotez PJ, Tsuji M (Eds.), Medical parasitology pp.146-152.

46. Pednekar RP, Gatne ML, Thompson RCA, Traub RJ (2009) Molecular and morphological characterization of Echinococcus from food producing animals in India. Veterinary Parasitology 165: 58-65.

47. Jones O, Kebede N, Kassa T, Tilahun G, Macias C (2011) Prevalence of dog gastrointestinal parasites and risk perception of zoonotic infection by dog owners in Wondo Genet, Southern Ethiopia. Journal of Public Health and Epidemiology 3: 550-555.

48. Erbeto K, Zewde G, Kumsa B (2010) Hydatidosis of sheep and goats slaughtered at Addis Ababa Abattoir: Prevalence and risk factors. Tropical Animal Health and Production 42: 803-805.

49. Fromsa A, Jobre Y (2011) Infection prevalence of hydatidosis (Echinococcus granulosus Batsch, 1786) in domestic animals in Ethiopia: A synthesis report of previous surveys. Ethiopian Veterinary Journal 15: 11-33.

50. Japheth M, Ernest N, Eberhard Z (2006) Epidemiology and control of echinococcosis in sub-Saharan Africa. Parasitology International 55: S193-S195.

51. Getaw A, Beyena D, Ayana D, Megersa B, Abunna F (2010) Hydatidosis: Prevalence and its economic importance in ruminants slaughtered at Adama municipal abattoir, Central Oromia, Ethiopia. Acta Tropica113: 221-225.

52. Eckert J, Gemmell MA, Meslin FX, Pawlowski ZS (2001) WHO/OIE Manual on Echinococcosis in humans and animals.

53. Torgerson PR (2003) Economic effects of Echinococcoses, Acta Tropical 85: 113-118.

54. Scala A, Garippa G, Varcasia A, Tranquillo VM, Genchi C (2006) Cystic echinococcosis in slaughtered sheep in Sardinia (Italy). Veterinary Parasitology 15(13): 33-38.
55. Alemu Y, Merkel RC (2008) Sheep and goats' production and Handbook for Ethiopia p. 2.

56. Andreas A (1997) The liver. In: Grainger and Allison's Diagnostic Radiology: A Textbook of Medical Imaging. ( $3^{\text {rd }}$ edn), Philadelphia, PA, USA: Churchill Livingstone pp. 1155- 1160.

57. Budke CM, Jiamin Q, Craig PS, Torgerson PR (2005) Canine echinococcosis in northwest Libya: assessment of coproantigen ELISA and a survey of infection with analysis of risk factors. Veterinary Parasitology 130: 223-232.

58. Center for Disease Control CDC (2006) Parasite Image Library: Echinococcosis. DPDx. CDC, Web. Elsevier pp. 224-231.

59. Communicable Diseases Common to Man and Animals CDC (2016) Scientific and Technical Publication No. 580. Parasitoses ( $3^{\text {rd }}$ edn), Washington, DC, USA, 3: 184-199.

60. Landes Bioscience, Austin, TX. Cysts in slaughtered animals in the Mazandaran Province, Northern Iran. Tropical Animal Health Production 41(8): 1701-1705.

61. Dalimi A, Motamedi G, Hosseini M, Mohammadian B, Malaki H, et al. (2002) Echinococcosis/ hydatidosis in western Iraq. Veterinary Parasitology 105: 161-171.

62. Eckert T, Deplazes P, Craig PS, Gemmell MS, Gottstein B, et al. (2001) Echinococcosis in animals: clinical aspects, diagnosis and treatment. In: Eckert J, Gemmell MA, Meslin FX, Pawlowski ZS, (Eds.), Echinococcosis in Humans and Animals: A Public Health Problem of Global Concern. Paris, France: World Organization for Animal Health p. 72-99.

63. Eisa AM, Mustafa AA, Soliman KN (1962) Preliminary Report on Cysticercosis and hydatidosis in Southern Sudan. Sudan Journal of Veterinary Science 3: 97-108.

64. Giro B (2015) Epidemiology, histopathology and public health significance in central Oromia, Ethiopia. journal of hydatidosis in ruminants and echinococcosis in dogs p. 48.

65. MS (2007) Review on prevention and control of cystic echinococcosis. Lancet Infectious Disease 7: 385-394.

66. Magambo J, Hall C, Zeyle E, Wachira T (1996) Prevalence of human hydatid disease in southern Sudan. African Journal of Health Sciences 3(4): 154-156.

67. Magambo JK, Zeyhle E, Wachira T (1997) Hydatid disease in Toposa land southern Sudan. African Journal Health Science 5(3-4): 129-132.

68. PACE-Ethiopia (Pan African Programme for the Control of EpizooticsEthiopia) (2003) Palmer SR, Biffin AH, Craig BPS, Walters TMH (1996) Control of Hydatidosis.

69. Stewart AJ, Plotkin JB (2013) Extortion and cooperation in the Prisoner's Dilemma. Proclamation National Acadamic Science USA, 109(26): 10134-10135. 


\section{Your next submission with Juniper Publishers} will reach you the below assets

- Quality Editorial service

- Swift Peer Review

- Reprints availability

- E-prints Service

- Manuscript Podcast for convenient understanding

- Global attainment for your research

- Manuscript accessibility in different formats ( Pdf, E-pub, Full Text, Audio)

- Unceasing customer service

Track the below URL for one-step submission https://juniperpublishers.com/online-submission.php 